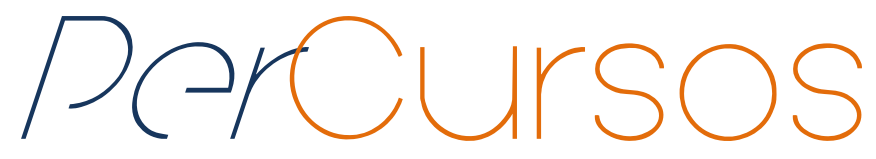

\title{
O papel da universidade no sistema paranaense de inovação de 2005 até 2015: o caso da UTFPR
}

\begin{abstract}
Resumo
A universidade apresenta um caráter metódico na contribuição para o avanço do conhecimento e da tecnologia no quadro econômico e social de um país por meio do ensino, da pesquisa e da extensão. O conhecimento gerado por pesquisas entre discentes e docentes pesquisadores pode promover a interação com vários atores, entre eles, universidade, empresas e governo, ocasionando a transferência da tecnologia gerada na universidade para o mercado. O objetivo geral deste estudo foi verificar o papel da Universidade Tecnológica Federal do Paraná (UTFPR) no sistema regional de inovação no período de 2005 até 2015. Para tanto, parte da pesquisa foca a interação da UTFPR com as empresas considerando as políticas nacionais e paranaenses e a transferência de tecnologia. Esta pesquisa se caracteriza por ser aplicada, descritiva e qualitativa, baseada no estudo de caso da UTFPR. Os dados primários foram levantados a partir de um questionário adaptado, com base nas questões aplicadas pelo FORMICT, que foram respondidos pelos Núcleos de Inovação Tecnológica da UTFPR. Os resultados mostram que, embora a UTFPR tenha apresentado maior interação com a indústria por meio de estágios, cursos de qualificação e in company, grupos de pesquisas e contratos de transferência de tecnologias, os entraves relacionados à burocracia organizacional, escassez de financiamento para a pesquisa científica e tecnológica e a falta de informação para os pesquisadores sobre o mercado são os principais entraves para alavancar tais interações.
\end{abstract}

Palavras-chave: Inovações tecnológicas - Paraná. Universidade e indústria. Transferência de tecnologia.

\section{Maria Lucia Figueiredo Gomes de Meza}

Doutora em Desenvolvimento Econômico pela UFPR.

Professora dos Programas de Pós-Graduação em Planejamento e Governança Pública e em Administração da UTFPR. malumeza@utfpr.edu.br

\section{Arion Bastos}

Mestre em Planejamento e Governança Pública pela UTFPR. Programa de Pós-Graduação em Planejamento e Governança Pública da UTFPR. arion.bastos@gmail.com

\section{Para citar este artigo:}

DE MEZA, Maria Lucia Figueiredo Gomes; BASTOS, Arion. O papel da universidade no sistema paranaense de inovação de 2005 até 2015: o caso da UTFPR. Revista PerCursos, Florianópolis, v. 19, n.40, p. 317 - 347, maio/ago. 2018.

\section{DOI: $10.5965 / 1984724619402018317$}

http://dx.doi.org/10.5965/1984724619402018317 


\title{
The role of the university in the Paranaense innovation system of 2005 to 2015: the case of UTFPR
}

\begin{abstract}
The university has a methodical character in the contribution to the advancement of knowledge and technology in the economic and social framework of a country through teaching, research and extension. The knowledge generated by research among students and faculty researchers can promote interaction with several actors, among them, university, companies and government, causing the transfer of the technology generated in the university to the market. The general objective of this study was to verify the role of the Federal Technological University of Paraná (UTFPR) in the regional innovation system in the period from 2005 to 2015. To that end, part of the research focuses on the interaction of UTFPR with companies considering national and paranaenses policies and technology transfer. This research is characterized by being applied, descriptive and qualitative, based on the case study of UTFPR. The primary data were collected from an adapted questionnaire, based on the questions applied by FORMICT, which were answered by UTFPR's Technological Innovation Centers. The results show that, although UTFPR has shown greater interaction with industry through internships, in-company and qualification courses, research groups and technology transfer contracts, obstacles related to organizational bureaucracy, lack of research funding scientific and technological information and the lack of information for researchers on the market are the main obstacles to leverage such interactions.
\end{abstract}

Keywords: Technological innovations - Paraná. University and industry. Technology transfer. 


\section{Introdução}

A capacidade de um país produzir riqueza e atingir um desenvolvimento sustentável está relacionada à sua competência em transformar ciência e tecnologia em inovação, e essa capacidade resulta da atuação e da interação de múltiplos agentes, tendo como destaques as empresas, universidades, institutos de pesquisa e o governo (FREEMAN, 1988; LUNDVALL, 1992).

Uma instituição que tem estado no centro das políticas de inovação é a universidade. Uma grande fatia dos progressos tecnológicos que tiveram rendimentos econômicos significativos está associada direta ou indiretamente à universidade seja pela oferta de treinamento, transmissão de conhecimentos, desenvolvimento de pesquisas ou por cooperações junto às empresas para o desenvolvimento de novas tecnologias (YUSUF, 2007; KENNEY; MOWERY, 2014).

Mesmo que sejam reconhecidas como importantes produtoras de novos conhecimentos, ainda assim, no Brasil as empresas utilizam muito pouco as universidades como fonte de inovação (COHEN, NELSON; WALSH, 2002; e LAURSEN; SALTER, 2004). Segunda dados da PINTEC 2014 (2016), 483 empresas implementaram inovação e receberam incentivos financeiros do governo por meio de financiamentos em projetos de $P \& D$ no Brasil em parceria com universidades, 0 equivalente a $58 \%$ do total das empresas ${ }^{1}$, enquanto que no estado do Paraná esta parceria totalizou 38 empresas, o correspondente a $72 \%$ do total, reconhecendo a importância da parceria do governo, universidades e empresas.

No entanto, realizar com sucesso essas parcerias não é simples, visto que a cooperação universidade-empresa (U-E) demanda mudanças em seus modelos institucionais e gerenciais e a superação de obstáculos organizacionais,culturais e estratégicos (COHEN; NELSON; WALSH, 2002).

Nas últimas três décadas, o Brasil empreendeu esforços no aperfeiçoamento de seus conhecimentos científicos e tecnológicos, acrescentando um conjunto de instituições relevantes para o Sistema Nacional de Inovação (SNI) com universidades conceituadas, formação de uma grande quantidade de doutores e vários planos governamentais de incentivo à inovação nas empresas (PEDROSA; QUEIROZ, 2014). No que se refere aos incentivos à inovação e à pesquisa

\footnotetext{
${ }^{1}$ Foram consideradas as empresas que implementaram produto e/ou processo novo ou substancialmente aprimorado.
} 
científica e tecnológica no ambiente produtivo, podemos citar: a Lei $n^{\circ}$ 10.332/2001, que instituiu 0 programa de inovação para competitividade; a Lei nº 10.973/2004 (Lei de Inovação), que possibilitou a cooperação entre instituições de pesquisa, universidades e empresas; a Lei n 11.196/2005 (Lei do Bem), que estabeleceu o regime especial de tributação para a plataforma de exportação de serviços de tecnologia da informação, o regime especial de aquisição de bens de capital e a inclusão digital; Projeto de Lei n 2.177/2011, que definiu o Código Nacional de Ciência, Tecnologia e Inovação e a Lei $n^{0} 13.243 / 2016$, que estabeleceu medidas de incentivo à inovação e à pesquisa científica e tecnológica no ambiente produtivo.

Nesse encadeamento de ideias, tornam-se importantes algumas reflexões a respeito das principais barreiras à promoção da inovação no país e da atuação dos três grandes atores envolvidos, empresas, universidades e institutos de pesquisa e o governo, com enfoque especial para as universidades, nas quais se centraliza a maior parcela da competência e das atividades nacionais de geração de novos conhecimentos científicos e tecnológicos do país.

Nas três últimas décadas, mundialmente, as universidades têm se organizado e evoluído para atuar de maneira efetiva nos sistemas nacionais de inovação (SNI), ao passo que as universidades no Brasil passaram a enfrentar esse novo desafio de modo intenso na última década. As universidades públicas no Brasil viram-se obrigadas a formular ou atualizar, a partir da Lei de Inovação, normas e políticas internas para sistematização e execução de proteção e gestão de sua propriedade intelectual, da mesma maneira determinar particularidades administrativas e procedimentos para sua transferência, negociação e licenciamento, a partir do disposto na nova legislação.

Para a universidade ser capaz de colaborar com o SNI de modo efetivo e abrangente, é essencial o desenvolvimento e a inclusão de novas atribuições e funções alémde seus tradicionais papéisde ensino, pesquisa e extensão, tais como, a gestão da propriedade intelectual; a cessão dos direitos para exploração; a gestão das interações entre universidades e empresas (U-E) em inovação; e o estímulo e apoio ao empreendedorismo (SIEGEL, D. S.; WESTHEAD, P.; WRIGHT, M. 2003a,b, 2007; LOCKET, A.; SIEGEL, D.; WRIGHT, M.; ENSLEY, M. 2005; GRIMALDI, R.; KENNEY, M.; SIGEL, D.S.; WRIGHT, M. 2011). 
O debate sobre a efetividade do papel das universidades nos SI não é recente, mas dado os atuais gargalos ainda não resolvidos no SI brasileiro, em parte devido à dificuldade de se estreitar as relações entre as universidades e as empresas, este artigo objetiva verificar como a universidade contribui para o sistema de inovação paranaense a partir do caso da UTFPR. Como a UTFPR tem contribuído para o sistema de inovação regional a partir de suas funções precípuas de ensino, pesquisa e extensão e considerando as políticas nacionais e paranaense de inventivo à inovação? E quais são os gargalos para uma maior interação com as empresas regionais?

Para tanto, este trabalho está dividido em seis partes. Após esta introdução, nas segunda e terceira partes se discutem a noção de sistemas de inovação e as relações entre as universidades, empresas e governo para promoção das inovações, respectivamente. Na quarta parte, o debate recai sobre o papel das políticas públicas de transferência de tecnologia no Brasil. Já na quinta parte, procura-se compreender como uma instituição pública de relevância regional contribui para 0 sistema regional de inovação, a partir do caso da UTFPR no Paraná. Nesta parte,considerando as formas de relacionamento da UTFPR com as empresas a partir de suas funções precípuas de ensino, pesquisa e extensão, analisa-se como a instituição tem contribuído para o sistema regional de inovação paranaense. E, na sexta e última parte são apresentadas as conclusões.

\section{Sistemas de inovação}

Um Sistema de inovação (SI) pode ser definido como o "conjunto de instituições, que contribuem para o desenvolvimento da capacidade de inovação e aprendizado de um país, região, setor ou localidade; e que também afetam tais espaços" (CASSIOLATO; LASTRES, 2005, p.37). Esse conceito se pauta no entendimento de que a inovação é um processo interativo que envolve diversos atores, reforçando a compreensão de que as empresas não inovam isoladamente, uma vez que para introduzir uma inovação, elas precisam interagir com outras empresas e organizações, tais como, universidades e institutos de pesquisa, instituições financeiras, instituições governamentais, entre muitas outras, trazendo a noção da inovação como um processo coletivo (MARLEBA, 2002).

É importante ressaltar as especificidades nacionais nos padrões de interação e cooperação entre atores de um Sistema Nacional de Inovação (SNI), uma vez que a forma e o grau em que se processam tais relações diferem entre localidades, especialmente em relação à extensão, natureza 
e motivação das colaborações. Consequentemente, o papel das universidades difere em intensidade e influência entre países e pode ser potencializado de acordo com a base industrial e com os incentivos e fundos públicos para a pesquisa científica da nação (NELSON, 1993; FREEMAN, 1988). Desse modo, o papel das universidades nos SI é determinado pelas características dos sistemasem que estão inseridas devendo ser analisado a partir de uma perspectiva sistêmica (NELSON, 1993; FREEMAN, 1988).

Nas últimas três décadas, têm-se percebido que a contribuição da universidade para o SI pode ser fortalecida quando ela estabelece uma atuação empreendedora e conexões bilaterais mais estreitas com a indústria, em especial, em nações emergentes. 0 grau de interação e de trocas de conhecimento e experiência entre os atores é um fator que distingue os SI mais avançados daqueles que ainda estão em desenvolvimento (MOWERY; SAMPAT, 2005). Dentre essas interações destacam-se as cooperações entre universidades, institutos de pesquisa e empresas, em especial por complementaridade e capacidade de resultar em benefícios para ambas as partes (FERNANDES, C.; ANGUITA, P. 2010).

Outra abordagem complementar à dos SNI é a dos Sistemas Regionais de Inovação (SRI), que deriva do delineamento daquele sistema e que tem como característica o tratamento da inovação de maneira localizada e evolutiva, tendo em vista os aspectos institucionais e sociais no qual a inovação surge. Um SRI segundo Doloreux (2003), é caracterizado, de um lado, pela cooperação entre as empresas nas atividades de inovação e, por outro lado, pela atuação de universidades, institutos de pesquisa, agências de transferência de tecnologia e organizações de treinamento criando e transmitindo conhecimento.

A origem do conceito de SRI é resultado da combinação de duas linhas teóricas de pesquisa (COOKE, P.; BOEKHOLT,P. 2000). A primeira delas é a literatura de SI, construída a partir das teorias evolucionárias de mudança tecnológica, que coloca a inovação como um processo de evolução e ao mesmo tempo um processo social, no qual o aprendizado coletivo acontece entre as diversas funçõesda empresa (P\&D, produção, marketing, etc.) e pela interação da empresa com o ambiente externo, como outras empresas provedoras de conhecimento e organizações de treinamento. A segunda é a economia regional, que procura delimitar o espaço geográfico da produção e das instituições conforme as características sociais, históricas e culturais (COOKE, et al., 2000). 
De acordo com Dororeux e Parto (2004), a noção de SRI sustenta-se em três conceitoschaves sobre as inovações. O primeiro é que as inovações acontecem em um ambiente institucional, político e social. Desta forma, eladepende das características locais que ocorrem regionalmente. $O$ segundo refere-se às inovações como resultados das relações sociais específicas de cada região em termos de cultura e outros fatores não percebidos, que afetam 0 relacionamento entre os atores. E o terceiro associa a maior facilidade de ocorrer a inovação dada a proximidade de concentração regional intelectual e empresarial. Desta forma, os "clusters" industriais são um elemento importante para o aprendizado do setor e do desenvolvimento de inovações, que ocorrem tanto a partir de mecanismos formais (a educação) como informais (o relacionamento entre os agentes e intercâmbio de pessoas entre as empresas) - (DOLOREUX e PARTO, 2004).

\section{A relação universidade, empresa e governo no sistema de inovação}

Neste artigo foi utilizado o conceito da Hélice Tríplice (ETZKOWITZ; LEYDSDORFF, 1997a,b) para compreender o relacionamento entre empresa, universidade, institutos de pesquisa e o governo no sistema de inovação ${ }^{2}$. Os papéis essenciais nos processos de inovação são desempenhados por três atores principais: a empresa, o governo e as universidades. 0 relacionamento entre esses três atores, permeado pelas redes de comunicação, compõe a Hélice Tríplice. Essa teoria não atribui um peso maior a determinado ator, apenas destaca que a empresa é o locus principal da inovação e não leva em consideração as diferenças setoriais e as distintas contribuições de cada setor. Ao analisar a relação entre os agentes estado, sistema produtivo (indústria) e universidades (academia) como um processo de desenvolvimento, o modelo Hélice Tríplice se distingue de outros dois modelos (Figura 1). O primeiro, denominado modelo estático, se caracteriza por ser um sistema dirigido pelo governo, por militares ou pelo partido, enquanto a sociedade civil, na medida em que aparece, é uma força de oposição a um regime autoritário. Já o modelo Laissez-faire caracteriza-se por ser constituído por esferas institucionais estritamente demarcadas, ou seja, os papéis dos três atores são isolados, sendo o governo o regulador das atividades, a academia a formadora de recursos humanos e a indústria a comerciante local das

\footnotetext{
${ }^{2}$ Outra teoria que trata de analisar a relação entre universidade, empresas e governo no sistema de inovação é o modo 2 de produção do conhecimento. Para saber mais ver Gibbons et al (1994).
} 
tecnologias desenvolvidas pela academia. Por fim, no modelo Hélice Tríplice, caracteriza-se pela interação relativamente igual entre os três atores.

Figura 1- Representações dos estágios de desenvolvimento da Hélice Tríplice

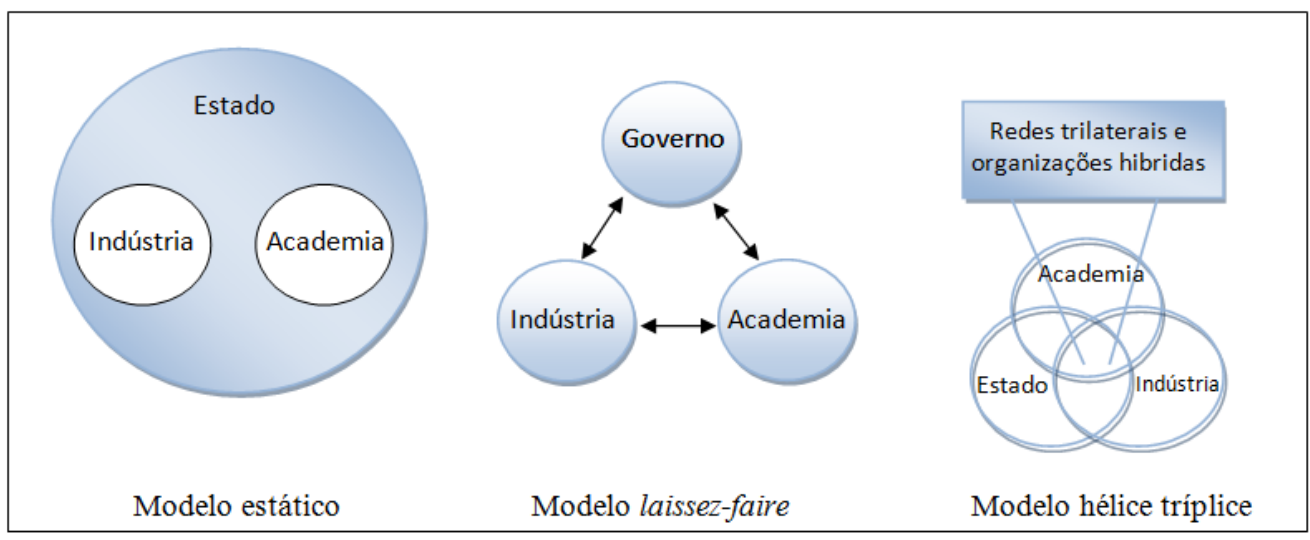

Fonte: Adaptado de Dossa (2010, p.1.333).

O argumento central na Hélice Tríplice é que as universidades têm um papel ampliado nas sociedades baseadas em conhecimento. Segundo os autores, as políticas industriais anteriores focavam na relação entre o governo e as empresas tanto por meio de incentivos, como redução de impostos, quanto por subsídios para a fixação em determinados locais. Em uma economia baseada no conhecimento, a universidade se torna um elemento-chave dos SI, tanto como fornecedora de capital humano, quanto fomentadora de novas empresas. Neste caso, a Hélice Tríplice se torna uma plataforma para a criação de novos formatos organizacionais promotores de inovação, tais como, incubadoras, parques tecnológicos e firmas de capital de risco.

Observa-se que um ponto-chave nas reformas recentes das políticas brasileiras de ciência, tecnologia e inovação (CT\&l) é a incorporação de instrumentos que favoreçam pesquisas para a produção de conhecimento estratégico para o país. Seu objetivo é influenciar a agenda da comunidade científica a incorporar mais a solução de problemas e questões externas, de modo a torná-la mais relevante para outros atores como empresas, governo e organizações sociais (BALBACHEVSKY, 2011).

Para Kenney e Mowery (2014), como muitos estudos empíricos sobre as conexões entre universidades e empresas (U-E) são baseados em análises setoriais das atividades de 
patenteamento e de licenciamento, a identificação da evolução dessas relações ao longo do tempo é negligenciada, além das relações serem imprecisamente caracterizadas como unidirecionais, envolvendo eminentemente fluxos de conhecimentos da academia para o mercado. Mesmo assim, constituem referências importantes para se compreender melhor os determinantes dessa relação.

Pesquisas recentes, por outro lado, apontam os efeitos positivos das conexões U-E no desempenho das pesquisas de grupos acadêmicos, uma vez que a interação entre grupos de pesquisa de excelência e empresas permitiu àqueles focar e complementar suas agendas de pesquisa, aproximando-as das comunidades nacionais relevantes em pesquisa e desenvolvimento $(P \& D)$. Para atingir esses objetivos, o importante é haver um equilíbrio entre a busca de conexões com empresas e a dedicação ao ensino e pesquisa básica (VAN LOOY et al., 2004; DEBACKERE; VEUGELERS, 2005).

As visões mais otimistas da cooperação U-E são contrabalanceadas por outras mais preocupadas com possíveis riscos relacionados aos efeitos dessa cooperação sobre os objetivos da pesquisa pública. Questiona-se a legitimidade dessa pesquisa ser ou não direcionada para resolver problemas de empresas, além da apropriação e uso dos seus resultados, pois muitas empresas exigem a exclusividade sobre as invenções, enquanto a prioridade de uma universidade pública deve ser a difusão do conhecimento que gera (GIULIANI; ARZA, 2009).

É importante considerar que a cooperação U-E em pesquisa, desenvolvimento e inovação (PD\&I) é um processo de aprendizado contínuo, que não acontece subitamente. A confiança é um elemento-chave para a sustentabilidade dessas parcerias em longo prazo, sendo conquistadas ao longo do tempo, conforme analisado por Botelho e Alves (2011).

\section{Políticas públicas de transferência de tecnologia}

A Transferência de Tecnologia entre universidades e empresas (TTUE) relaciona-se à inovação na geração de recursos financeiros reinvestidos no estímulo de novas ou mais desenvolvidas pesquisas científicas realizadas pelas universidades (DIAS; PORTO, 2014).

Na atualidade, um dos principais modos de alavancar políticas na área de ciência e tecnologia é por meio de processos de cooperação U-E. Segatto-Mendes e Sbragia (2002) 
expressam a cooperação U-E como um processo de transferência de produtos e/ou serviços, que visam o desenvolvimento da base de conhecimento dos participantes.

A não existência de uma política brasileira abrangente e consistente de fomento a TTUE faz com que os resultados da pesquisa acadêmica científica, subsidiada com recursos públicos, não sejam repassados à sociedade de acordo com a adequada necessidade de desenvolvimento do país (FUJINO; STAL, 2007).

As legislações vigentes sobre transferência de tecnologia no Brasil são promulgadas por meio de leis e decretos (Quadro 1) e não versam sobre o intercâmbio entre U-E de maneira específica e direta.

Quadro 1-Legislações brasileiras relacionadas à transferência de tecnologia.

\begin{tabular}{|c|c|}
\hline Decreto-Lei nº 7.903/45 & $\begin{array}{l}\text { Regula os direitos e obrigações concernentes à propriedade } \\
\text { industrial e em sua função econômica e jurídica.Instituiu o Código } \\
\text { de Propriedade Industrial. }\end{array}$ \\
\hline $\begin{array}{l}\text { Lei } \mathrm{n}^{\circ} 5 \cdot 648 / 70 \text { - Instituto Nacional } \\
\text { de Propriedade Indústria (INPI) }\end{array}$ & $\begin{array}{l}\text { Executa, no âmbito nacional, as normas que regulam a } \\
\text { propriedade industrial. }\end{array}$ \\
\hline Lei $\mathrm{n}^{\circ} 8.248 / 91$ & $\begin{array}{l}\text { Dispõe sobre a capacitação e competitividade do setor de } \\
\text { informática e automação. }\end{array}$ \\
\hline Lei $\mathrm{n}^{\circ} 8.661 / 93$ & $\begin{array}{l}\text { Dispõe sobre os incentivos fiscais para a capacitação tecnológica } \\
\text { da indústria e da agropecuária. }\end{array}$ \\
\hline $\begin{array}{l}\text { Lei } \mathrm{n}^{\circ} \text { 9.279/96 - Lei de Propriedade } \\
\text { Industrial ou Marcas e Patentes }\end{array}$ & $\begin{array}{l}\text { Proporcionou a proteção tecnológica nos setores em que a } \\
\text { pesquisa acadêmica do país era relevante. }\end{array}$ \\
\hline Lei $n^{\circ} 10.168 / 2000$ & $\begin{array}{l}\text { Regulamenta o financiamento do Programa de Estímulo à } \\
\text { Interação Universidade-Empresa para o apoio à Inovação. }\end{array}$ \\
\hline $\begin{array}{l}\text { Lei n. } 0^{\circ} 10.973 / 2004-\text { Lei de } \\
\text { Inovação }\end{array}$ & $\begin{array}{l}\text { Possibilita a cooperação entre instituições de pesquisa, } \\
\text { universidades e empresas, entretanto, não normatiza } \\
\text { procedimentos claros e específicos que possibilitem a TTUE de } \\
\text { maneira apropriada. }\end{array}$ \\
\hline Lei nº 11.196/2005 - Lei do Bem & $\begin{array}{l}\text { Institui o regime especial de tributação para a plataforma de } \\
\text { exportação de serviços de tecnologia da informação, o regime } \\
\text { especial de aquisição de bens de capital para empresas }\end{array}$ \\
\hline
\end{tabular}




\begin{tabular}{|l|l|}
\hline & $\begin{array}{l}\text { exportadoras e o programa de inclusão digital; e dispõe sobre } \\
\text { incentivos fiscais para a inovação tecnológica. }\end{array}$ \\
\hline $\begin{array}{l}\text { Leis estaduais de incentivo à } \\
\text { inovação (desde 2006) }\end{array}$ & $\begin{array}{l}\text { Implementadas através de mecanismo regulatório desde 2006, } \\
\text { sendo reproduções da Lei Federal } n^{\circ} 10.973 / 2004 \text {, só que de } \\
\text { aplicação estadual. }\end{array}$ \\
\hline $\begin{array}{l}\text { Lei } \mathrm{n}^{\circ} 13.243 / 2016, \text { decorrente do } \\
\text { Projeto de Lei } \mathrm{n}^{\circ} \mathbf{2 . 1 7 7 / 1 1}\end{array}$ & $\begin{array}{l}\text { Estabelece medidas de incentivo à inovação e à pesquisa científica } \\
\text { e tecnológica no ambiente produtivo, com vistas à capacitação } \\
\text { tesenvolvica, ao alcance da autonomia tecnológica e ao } \\
\text { país. }\end{array}$ \\
\hline
\end{tabular}

Fonte: Elaboração própria.

No que diz respeito às leis estaduais de incentivo à inovação,elas já foram deferidas em aproximadamente 16 estados do Brasil, sendo reproduções da Lei Federal $n^{0}$ 10.973/2004, aplicadas no âmbito estadual e que não solucionam as dificuldades encontradas na própria Lei de Inovação. Elas estabelecem medidas para fortalecer o SRI, voltadas aos seus parques tecnológicos, incubadoras de empresas locais além de incentivos econômicos e fiscais para projetos de inovação das empresas no estado. No Paraná, a Lei $n^{0}$ 17.314/2012 regulamentou tais ações e teve como base os estudos das legislações já efetivas e na vivência de profissionais, que colaboraram na elaboração da Lei Federal e da Comissão de Estudos Especial da Associação Brasileira de Normas Técnicas (ABNT/CEE-130), que formulou as normas brasileiras (NBR) para Gestão da Pesquisa, Desenvolvimento e Inovação (PD\&I). Desse modo, ampliou-se a concepção presente na maioria das leis estaduais com a finalidade de abranger também as inovações organizacionais e sustentáveis.

Em síntese, os dez capítulos da Lei do Estado do Paraná estabelecem os alicerces que asseguram a segurança jurídica a fim de que os atores públicos e privados sejam capazes de interagir e produzir conhecimentos resultando em inovação.

Para o crescimento da TTUE, torna-se imprescindível uma forte política pública nacional que apoie a disseminação da propriedade intelectual, promovendo o diálogo entre as universidades, o governo e o setor produtivo (CORRÊA, 2000) e unificando esforços para superar os obstáculos que este processo tem enfrentado. Para isso, a necessidade da institucionalização dos NITs foi um dos instrumentos que o governo sugeriu para encurtar a distância entre a academia e o ambiente 
empresarial, uma enorme barreira para a viabilização da TT e, consequentemente, da inovação (DECTER; BENNETT; LESEURE, 2007).

Certas barreiras ainda continuam, especialmente a que corresponde à burocracia do serviço público e aos procedimentos de gerenciamento da TTUE. Por outro lado, as políticas institucionais de avaliação e de fomento à pesquisa do governo tendem a valorizar quase que somente as publicações científicas e não o desenvolvimento de produtos e patentes oriundo dos pesquisadores (CORRÊA, 2007; AMADEI; TORKOMIAN, 2009). Por fim, também se encontra dificuldade para conseguir financiamentos no Brasil (SEGATTO-MENDES; SBRAGIA, 2002) e a utilização de recursos financeiros dos órgãos de fomento é direcionada, primeiramente, para a pesquisa teórica, pois a pesquisa aplicada requer mais recursos e infraestrutura mais complexa e dispendiosa (CORRÊA, 2000). Além disso, existe a escassez de recursos para fabricar protótipos, que materializem resultados de pesquisa e viabilizem sua comercialização (SANTANA; PORTO, 2009).

\section{A contribuição da UTFPR no sistema paranaense de inovação}

Os dados apresentados nesta parte da pesquisa são resultados das pesquisas bibliográfica, documental e de campo realizadas. Os dados sobre alunos, egressos, estágios, visitas e ações empreendedoras foram obtidos por documentos (relatórios de gestão) e site institucionais. Já os dados sobre patentes foram levantados no banco de dados do Instituto Nacional da Propriedade Intelectual (INPI) e nos núcleos de inovação tecnológica (NIT) da instituição. Para caracterizar os grupos de pesquisa, utilizou-se o diretório dos grupos de pesquisa no Brasil do CNPq. E, os dados sobre a transferência de tecnologia foram obtidos através de questionário adaptado pela pesquisa feita pelo FORMICT/MCTI e aplicado aos 13 responsáveis pelos NIT da UTFPR. A análise do papel da UTFPR no sistema paranaense de inovação delimitou-se a partir de 2005 porque foi um ano logo após a formalização da primeira lei de inovação no país, Lei nº 10.973, de 02/12/2004.

Pesquisa recente (BASTOS, 2017) mostra que o sistema paranaense de Inovação é composto pelos seguintes agentes: empresas e instituições com atuação na área de pesquisa, desenvolvimento e inovação; instituições de ensino; instituições científicas e tecnológicas do Paraná (Tecpar e o IAPAR); agências de fomento financeiro à pesquisa (Fundação Araucária de Apoio ao Desenvolvimento Científico e Tecnológico do Paraná FUNPAR e Unidade Gestora do 
Fundo Paraná - UGF/ SETI); órgãos públicos (Conselho Paranaense de Ciência e Tecnologia - CCT,

Secretaria de Ciência, Tecnologia e Ensino Superior do Estado - SETI); incubadoras de empresas e parques tecnológicos do estado do Paraná.

A UTFPR, como um dos agentes que compõem o SI do Paraná é uma instituição pública federal que promove o ensino, a pesquisa e a extensão. Para Pedrosa (2014), o propósito da universidade é associar suas funções de ensino, pesquisa e extensão ao desenvolvimento econômico, tanto para a qualificação de pessoal para o sistema produtivo, quanto para a pesquisa científica, que se compreende como conhecimento científico-tecnológico. Desta forma, a UTFPR, por meio de seus campi localizados em 13 municípios do estado do Paraná é agente relevante no desenvolvimento regional.

A UTFPR é a primeira universidade denominada tecnológica no Brasil em virtude de sua herança na formação de profissionais técnicos. Ela foi fundada no início do século XIX como Escola de Aprendizes Artífices e, depois de passar por várias mudanças institucionais (como Liceus e escolas técnicas), passou a ser o Centro Federal de Educação Tecnológica do Paraná (CEFET-PR). Por esta razão, ela foi criada como universidade com um propósito distinto das universidades tradicionais, pois seu foco deve ser no comprometimento com a pesquisa aplicada. Como instituição federal de ensino público, ela é uma autarquia vinculada ao Ministério da Educação MEC, tendo como finalidades a formação e a qualificação de profissionais nas diversas modalidades e níveis de ensino para os mais variados setores da economia, assim como a realização de pesquisa e desenvolvimento tecnológico de novos processos, produtos e/ou serviços em estreita articulação com os setores produtivos e a sociedade, fornecendo mecanismos para a educação continuada (UTFPR, 2016). Com 12 anos de existência como universidade, hoje ela oferece cerca de 100 cursos superiores de tecnologia, bacharelados e licenciaturas; 19 cursos técnicos em diversas áreas do mercado (técnicos de nível médio integrado e cursos técnicos de nível médio subsequentes na modalidade a distância, com polos distribuídos pelos estados do Paraná e de São Paulo); e 146 cursos de pós-graduação. Possui 2.809 professores e 1.176 técnicos-administrativos e atende aproximadamente 32 mil alunos (UTFPR, 2016). Destes professores, 2.459 têem dedicação exclusiva, sendo 1.672 doutores, 962 mestres, 138 especialistas e 37 graduados (UTFPR, 2016). Ela forma, em média, 2.300 profissionais sendo a segunda instituição de ensino no estado paranaense a desenvolver tecnologias ( 140 pedidos de patentes e registros no INPI) e estabelece relacionamento 
com cerca de 4.667 empresas na região para fins de oportunizar acesso aos discentes ao mercado de trabalho, por meio de estágios e pesquisas, além de realizar trabalhos de consultorias e de pesquisa científica e tecnológica, por meio de compartilhamento de laboratórios, parcerias e acordos; e licenciamentos.

Nas últimas décadas, as universidades se consolidaram como espaços de desenvolvimento e disseminação de pesquisas científicas, além da tradicional função de formadora de profissionais. Um dos meios que ajudam no alicerce do crescimento científico, em âmbito universitário, são os Grupos de Pesquisas (GP), "responsáveis pela investigação de temáticas relevantes no âmbito científico, conduzem o debate e acirram o saber-fazer contribuindo, sobremaneira, para a construção de conhecimentos" (SILVA; CASIMIRO; DUARTE, 2016, p. 15). Tais conhecimentos não se limitam à natureza científica, mas transbordam para a tecnológica e são constituídos, muitas vezes, em parcerias com outras instituições de ensino e o sistema produtivo. Além disso, as atividades extensionistas também são oportunidades para um maior estreitamento com o seu entorno, inclusive para promover maior visibilidade das tecnologias desenvolvidas pela universidade.

Ao tratarmos de caracterizar a UTFPR a partir do debate do modelo Hélice Tríplice (ETZKOWITZ, 2008), podemos verificar que a instituição migrou de um Modelo Laissez-faire, no qual as atuações do governo, indústria ou sistema produtivo e universidade eram isoladas, ou seja, o governo sendo responsável pelas atividades regulatórias, a indústria ou sistema produtivo pela aplicação local de tecnologias, que podem ser transferidas da universidade; e a universidade limitando-se à formação de recursos humanos, à geração de conhecimento científico e tecnológico e às atividades extensionistas; para o modelo Hélice Tríplice. Hoje existe uma série de ações que a aproximam desse modelo, pois ela tem contribuído para a geração de novas empresas localmente, a partir de suas políticas de incentivo ao empreendedorismo, por meio de empresas incubadas e do hotel tecnológico, que traduzem conhecimento em atividade econômica; além de uma série de tecnologias criadas pelos seus servidores e discentes. Essas ações retratam uma forma dinâmica de interagir com o seu entorno (empresas e governo) para promover o desenvolvimento por meio da inovação e do empreendedorismo. Tais ações serão detalhadas no item seguinte. 


\section{Interações entre a UTFPR e as empresas no sistema regional de inovação}

\section{paranaense}

Considerando o modelo Hélice Tríplice (ETZKOWITZ; LEYDSDORFF, 1997a,b), neste item, pretende-se discutir as possibilidades de relacionamento entre a UTFPR e as empresas para promover mais inovações regionalmente. Esse debate se fundamenta nas seguintes atividades desenvolvidas pela UTFPR em interação com o seu entorno: estágios, visitas técnicas, cursos de treinamento in company e de qualificação profissional, grupos de pesquisa, transferências de tecnologias e promoção do empreendedorismo. A UTFPR oferece grande parte dessas atividades por meio da Pró-Reitoria de Relações Empresariais e Comunitárias (PROREC) e de suas diretorias, que realizam um dos macroprocessos finalísticos da instituição. Esse macroprocesso tem como objetivo ofertar cursos de educação continuada, estágios e empregos, acompanhamento de egressos, transferência de tecnologia, propriedade intelectual, empreendedorismo, extensão social e relações internacionais. APROREC e suas diretorias são responsáveis por planejar, coordenar e supervisionar a execução dessas ações, além de promover a interação da Instituição com o setor produtivo e a comunidade.

A UTFPR como instituição de ensino formadora de profissionais nos níveis técnico e superior e atendendo à legislação nacional, conforme a área de formação, oferece diversas oportunidades de estágios em parceria com as empresas locais. A UTFPR, ao se associar às empresas para oferecer estágios curriculares, proporciona aos discentes experiências profissionais e pessoais, maior capacitação acadêmica a partir de práticas profissionais e acesso à aplicação de novas ferramentas e instrumentos relacionados à área de formação do discente. Essa atividade consiste uma forma de transferir conhecimento para o seu entorno e possíveis oportunidades de gerar tecnologias e inovações no mundo do trabalho. Para Santana e Porto (2009), essas possibilidades de transferência de conhecimento e de tecnologias constituem canais de inovação.

Entre 2015-16, houve um incremento de 13\% no número de empresas cadastradas no sistema de Estágio da UTFPR, aumentando de 9.285 para 10.560. Destas, 4.667 fizeram uso do Sistema de Estágio ao longo de 2016 para disponibilizar vagas. Neste ano, foram assinados 4.597 contratos de estágio, possibilitando a transferência de conhecimento entre as empresas e estagiários. 
No caso das visitas técnicas, essas atividades se caracterizam como uma modalidade didática de ensino sobre os aspectos operacionais, funcionais e de instalações físicas de uma empresa ou organização promovendo a difusão e transferência de tecnologia. Já as visitas gerenciais têm por objetivo promover a interação da universidade com o mundo do trabalho; prospectar projetos e serviços tecnológicos; estudar novas possibilidades de convênios institucionais e empresariais; e formar parcerias.

Em 2015, houve uma pequena redução na quantidade de visitas técnicas (452) contra 512, em 2014, não caracterizando uma mudança significativa em função da estabilização na expansão do sistema UTFPR. Já as visitas gerenciais apresentaram uma diminuição significativa em 2015 (294) em relação ao ano de 2014 (431). Isso pode ser explicado pela mudança do perfil dos docentes, que cada vez focam mais nas atividades de pesquisa científica e em publicações, negligenciando as atividades de consultoria, que era uma prática muito mais recorrente na época em que a instituição, como CEFET-CT, era focada na educação técnica, tecnológica e profissional. Por outro lado, dada a crise econômica pela qual o país passou, é natural que as empresas busquem menos as universidades para resolução de problemas.

No que se refere à oferta de cursos in company e de qualificação profissional, a UTFPR tem uma tradição na oferta desses tipos de cursos, normalmente sob demanda, que objetivam proporcionar formação complementar à comunidade. Esses cursos são oferecidos em diferentes modalidades podendo variar desde o treinamento específico de determinada tecnologia para funcionários de uma empresa até cursos de determinado assunto de interesse geral da comunidade. 
O Quadro 2 apresenta a evolução da oferta destes cursos que, entre 2005-16 cresceu em número de cursos e de matriculados em $36,9 \%$ e 45,1\%, respectivamente. Esses cursos também representam possibilidades de transferência de conhecimento e de tecnologias entre a universidade e as empresas e, por conseguinte, constituem canais de fontes de inovação para as empresas.

Quadro 2-Número de oferta de cursos de qualificação profissional e de matriculados da UTFPR entre 2005 e 2016

\begin{tabular}{|l|l|l|l|l|l|l|}
\hline Anos & $\begin{array}{l}\text { Número de } \\
\text { cursos }\end{array}$ & $\begin{array}{l}\text { Número de } \\
\text { alunos }\end{array}$ & Anos & $\begin{array}{l}\text { Número de } \\
\text { cursos }\end{array}$ & $\begin{array}{l}\text { Número } \\
\text { alunos }\end{array}$ \\
\hline 2016 & 345 & 7.537 & 2010 & 294 & 5.542 \\
\hline 2015 & 301 & 7.024 & 2009 & 299 & 8.287 \\
\hline 2014 & 125 & 2.249 & 2008 & 245 & 5.046 \\
\hline 2013 & 326 & 7.703 & 2007 & 276 & 5.426 \\
\hline 2012 & 288 & 5.872 & 2006 & 252 & 5.195 \\
\hline 2011 & 356 & 8.062 & 2005 & - & - \\
\hline
\end{tabular}

Fonte: UTFPR, (2016, 2015, 2014, 2013, 2012, 2011, 2010, 2009, 2008, 2007, 2006, 2005).

Em relação aos Grupos de Pesquisa (GP), na UTFPR, a Pró-Reitoria de Pesquisa e PósGraduação (PROPPG), junto às Diretorias de Pesquisa e Pós-Graduação de seus 13 Campi, acompanham e promovem a consolidação dos GP através das diretrizes para a sua criação assim como os regulamentos, normas e políticas para manutenção deles.

Nos últimos anos, houve um crescimento no número de GP na UTFPR, totalizando 461 grupos de pesquisa cadastrados no Diretório dos Grupos de Pesquisa no Brasil (CNPq, 2016).

Pode-se verificar no Gráfico 1 que o maior número de grupos de pesquisa da UTFPR está na faixa entre 1 e 4 anos. Em parte, esses dados mostram que, por ser uma universidade jovem, com 12 anos, a UTFPR ainda está em fase de crescimento nas suas atividades de pesquisa. 


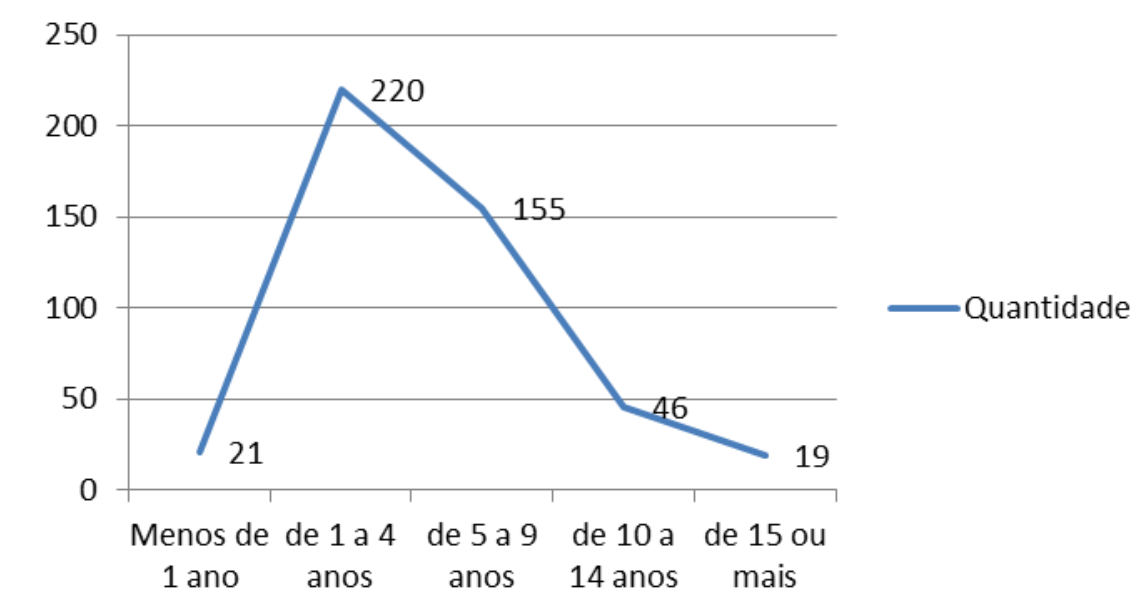

Fonte: CNPq (2016).

Destes 461 GP, constatou-se que a maioria é da área de Engenharia (208), seguidos das seguintes áreas: Ciências Exatas e da Terra (89), Ciências Humanas (54), Ciências Agrárias (40), Ciências Sociais Aplicadas (23), Linguística, Letras e Artes (19), Ciências Biológicas (16) e Ciência da Saúde(12).

Quanto à interação dos GP com as empresas, pode-se verificar, através do Quadro 3, a evolução do número de GP da UTFPR, que relataram ter, pelo menos, um relacionamento com empresas. Entre 2006 e 2016, o número destes GP cresceu 766,7\% (a). Um aumento maior que o comparado ao número total dos GP na instituição (406,6\%) - (b), representando 33,8\% destes grupos.

Quadro 3 - Números de grupos de pesquisa de relacionamento com a empresas e número total de grupos de pesquisa

\begin{tabular}{|l|l|l|}
\hline Ano & $\begin{array}{l}\mathrm{N}^{\circ} \text { de grupos de pesquisa de relacionamento com } \\
\text { as empresas da UTFPR (a) }\end{array}$ & $\begin{array}{l}\mathrm{N}^{\circ} \text { total dos grupos de pesquisa } \\
\text { (b) }\end{array}$ \\
\hline 2016 & 156 & 461 \\
\hline 2014 & 108 & 423 \\
\hline 2010 & 37 & 223 \\
\hline 2008 & 28 & 142 \\
\hline 2006 & 18 & 91 \\
\hline
\end{tabular}

Fonte: CNPq (2016) 
No que se refere ao número de participantes dos GP, a UTFPR apresentou um aumento de $891 \%$ de estudantes e 788\% de pesquisadores, entre 2006 e 2014. Essa evolução se deu devido à contratação de novos docentes e ampliação de cursos, vagas e infraestrutura. Além disso, fomentou-se a pós-graduação, incentivando o ingresso de docentes doutores,que criaram novos GP e desenvolveram projetos de pesquisa; além de se envolverem na pós-graduação stricto sensu e orientarem alunos da graduação em iniciação científica e alunos da pós-graduação stricto sensu.

Gráfico 2 - Quantidade de participantes por categoria nos grupos de pesquisa na UTFPR

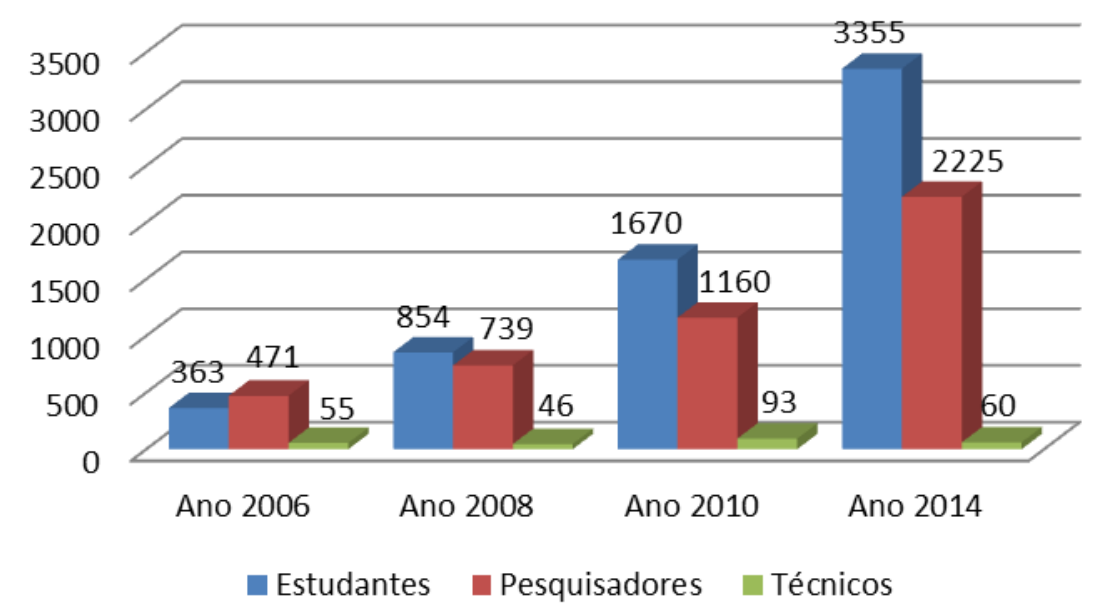

Fonte: CNPq (2015).

Em relação às transferências de tecnologias realizadas por meio de patentes e registros criados pelos professores e discentes, essa atividade é promovida e coordenada pela Agência de Inovação (AGINT) da UTFPR. Criada em 2007, ela tem como objetivo identificar oportunidades e incentivar a inovação, como nicho de mercado, amparados pela Proteção Intelectual, por meio da transferência de tecnologia. Cabe à AGINT, na medida do interesse institucional, apoiar a transferência de tecnologia, estimular o patenteamento e o registro das demais criações intelectuais, promovendo o marketing e auxiliando o pesquisador no licenciamento, cessão ou transferência de tecnologias desenvolvidas. Essa ação visa trazer maior interação da UTFPR com sistema produtivo, contribuindo para o desenvolvimento econômico e tecnológico local.

No ano de 2016, a AGINT totalizou 140 pedidos de propriedades intelectuais protegidas no Instituto Nacional de Propriedade Industrial (INPI), representante oficial do governo brasileiro para 
patentes e registros (patente de invenção, modelo de utilidade, desenho industrial, marcas, registro de software, indicação geográfica, dentre outros), um aumento de 1.455,6\% na proteção intelectual produzida na Universidade em nove anos, de 9 pedidos, em 2007, para 140, em 2016.

O Quadro 4 apresenta o quantitativo de pedidos formalmente protocolados até 2016, junto à AGINT.

Quadro 4-Número de pedidos de patentes e registros protocolados na AGINT da UTFPR

\begin{tabular}{|l|l|l|l|l|l|l|l|l|l|l|}
\hline Tipo & $\mathbf{2 0 1 6}$ & $\mathbf{2 0 1 5}$ & $\mathbf{2 0 1 4}$ & $\mathbf{2 0 1 3}$ & $\mathbf{2 0 1 2}$ & 2011 & 2010 & 2009 & 2008 & 2007 \\
\hline Patente de invenção & 110 & 84 & 62 & 51 & 10 & 09 & 06 & 05 & 05 & 05 \\
\hline Modelo de utilidade & 01 & 01 & - & - & - & & & & & \\
\hline Marcas & 10 & 08 & 06 & 06 & 04 & 02 & 02 & 02 & 02 & 02 \\
\hline Registro de software & 18 & 15 & 13 & 06 & 02 & 02 & 02 & 02 & 02 & 02 \\
\hline $\begin{array}{l}\text { Topografia de circuito } \\
\text { integrado }\end{array}$ & 01 & 01 & - & - & - & & & & & \\
\hline \begin{tabular}{l} 
Total \\
\hline
\end{tabular} & 140 & 109 & 81 & 63 & 16 & 13 & 10 & 09 & 09 & 09 \\
\hline
\end{tabular}

Obs.: Os dados computam o total acumulado por ano.

Fonte: UTFPR (2016, 2015, 2014, 2013, 2012, 2011, 2010, 2009, 2008, 2007).

A ACINT operacionaliza suas ações por meio dos Núcleos de Inovação Tecnológica (NIT). O objetivo desses núcleos é disponibilizar mecanismos de proteção da propriedade intelectual e estruturar meios para o fomento do empreendedorismo e da inovação. Em cada um dos 13 campi da UTFPR, há um NIT.

Para um melhor entendimento das ações realizadas pelos NIT da UTFPR foram enviados questionários aos responsáveis desses núcleos. Dos 13 campi, três não responderam à pesquisa, a saber: Apucarana, Guarapuava e Santa Helena.

A pesquisa constatou 183 contratos de transferência de tecnologia. A prática mais usual na UTFPR é o tipo de contrato por acordo de parceria de pesquisa, desenvolvimento e inovação, conforme ilustra o Quadro 5, a seguir.

Quadro 5 - Distribuição dos contratos de tecnologia por objeto nos NIT da UTFPR em 2016 


\begin{tabular}{|l|l|l|}
\hline Objeto & Quantidade & $\%$ \\
\hline $\begin{array}{l}\text { Contrato de licenciamento de direitos de propriedade intelectual } \\
\text { (Patente / Desenho Industrial / Marca / Programa de computador / } \\
\text { Topografia de circuito integrado / Cultivar / Obra literária, artística ou } \\
\text { científica / Outros) }\end{array}$ & 8 & $4 \%$ \\
\hline $\begin{array}{l}\text { Acordo de parceria de pesquisa, desenvolvimento e inovação (atividades } \\
\text { conjuntas de pesquisa científica e/ou tecnológica e desenvolvimento de } \\
\text { tecnologia, produto ou processo). }\end{array}$ & 75 & $41 \%$ \\
\hline $\begin{array}{l}\text { Contrato de know-how (envolvendo ativos intangíveis não amparados } \\
\text { por direitos de propriedade intelectual), assistência técnica (contração } \\
\text { de soluções técnicas ou capacitação e treinamento) e demais serviços. }\end{array}$ & 36 & $20 \%$ \\
\hline Acordo de confidencialidade & & \\
\hline $\begin{array}{l}\text { Contrato de co-titularidade } \\
\text { equipamentos, instrumentos, materiais e instalações }\end{array}$ & $7 \%$ \\
\hline Contrato ou convênio de permissão de utilização de laboratórios, & 43 \\
\hline
\end{tabular}

Fonte: Elaborado a partir da coleta de dados da pesquisa

Os dados mostram ainda que as parcerias de PD\&l, contratos ou convênios de compartilhamento e os contratos de know-how são também relevantes, quiçá por ser uma instituição tradicional em formação profissional e técnica, possuidora de inúmeros laboratórios e mantendo frequente contato com o sistema produtivo, por meio de estágios e ofertas de cursos de qualificação. Esse perfil se difere do nacional, no qual prevalecem os contratos de licenciamento de direito de propriedade intelectual.Estes resultados coincidem com a percepção dos responsáveis do NIT, que declararam ser as pesquisas, os estágios e os serviços laboratoriais os principais tipos de relacionamentos que a UTFPR estabelece com a indústria, seguidos pelas parcerias, cooperações, convênios e consultorias.

E, apesar dos fatores positivos, como o auxílio na disseminação da cultura de inovação quando os NIT foram implementados, a pesquisa também constatou desafios a serem enfrentados segundo a percepção dos responsáveis pelos NIT. Eles declararam como problemas e/ou obstáculos de elevado grau de importância a falta de informação sobre o mercado (para $25 \%$ dos pesquisados) 
e com grau médio de importância, a rigidez organizacional e a falta de pessoal qualificado e de informação sobre a tecnologia (13\% para cada obstáculo). Eles apontaram também o problema da escassez de fontes apropriadas de financiamento e a dificuldade para se adequar a padrões, normas e regulamentações. Já com baixo grau de importância, foram destacadas a escassez de serviços técnicos externos adequados e a centralização da atividade inovativa em outra empresa do grupo.

Apesar de todas essas iniciativas a respeito da interação da UTFPR com as empresas, percebe-se que barreiras de interação, tais como, o sigilo, a propriedade intelectual e a complexidade de contratos; como também as barreiras legais inerentes à transferência de tecnologia, ambos acabam gerando grandes incertezas para as empresas. Percebe-se ainda que o aprendizado por meio da interação universidade e empresa é fundamental, fazendo-se necessário que esta intensifique sua relação para maximizar, dessa forma, seu poder inovativo.

Por fim, outra atividade realizada no âmbito da UTFPR para gerar maior aproximação do acadêmico com o mercado de trabalho é a promoção de atividades empreendedoras por meio do hotel tecnológico (HT) e das incubadoras de inovação tecnológica (IIT).

O Hotel Tecnológico (HT) da UTFPR, por intermédio do programa de pré-incubação, viabilizou desde a sua implantação a inserção de mais de 120 empresas com potencial inovador no mercado ou em organizações incubadoras paranaenses. Essas ações estão vinculadas ao Programa de Empreendedorismo e Inovação - PROEM, que foi criado em 1997 para promover a cultura empreendedora na instituição por meio da oferta de disciplinas e espaços para desenvolver projetos de empresas de base tecnológica e inovação.

O Quadro 6 apresenta a evolução do número de projetos pré-incubados e de alunos participantes entre 2005 e 2015. Os dados mostram que estes números vêm aumentando nos últimos anos devido à instalação dos HT nos campus da UTFPR, como também devido ao trabalho realizado pelos NIT em estimular a participação dos alunos.

Quadro 6 - Número de projetos pré-incubados e de alunos participantes.

\begin{tabular}{|l|l|l|l|l|l|}
\hline Ano & $\begin{array}{l}\mathrm{N}^{\circ} \text { de projetos de } \\
\text { empresas }\end{array}$ & $\begin{array}{l}\mathrm{N}^{\circ} \\
\text { participantes }\end{array}$ & Ano & $\begin{array}{l}\mathrm{N}^{\circ} \text { de projetos de } \\
\text { empresas }\end{array}$ & $\mathrm{N}^{\circ}$ de participantes \\
\hline
\end{tabular}




\begin{tabular}{|l|l|l|l|l|l|}
\hline 2015 & 53 & 139 & 2009 & 26 & 71 \\
\hline 2014 & 44 & 110 & 2008 & 33 & 102 \\
\hline 2013 & 43 & 116 & 2007 & 25 & 74 \\
\hline 2012 & 41 & 118 & 2006 & 29 & 78 \\
\hline 2011 & 38 & 97 & 2005 & 29 & 98 \\
\hline 2010 & 30 & 77 & & & \\
\hline
\end{tabular}

Fonte: UTFPR (2015).

Ressalta-se que,em 2015,0s HT da UTFPR disponibilizaram 60 vagas para novos projetos e receberam 78 propostas, destas 53 foram aceitas. Essa procura revela que as ações de propagação da cultura empreendedora produziram uma mobilização da comunidade interna em participar de ações empresariais.

Outra ação também promotora do empreendedorismo é o espaço de incubação na universidade. A Incubadora de Inovações da Universidade Tecnológica (IUT) é uma incubadora de base tecnológica, localizada na UTFPR, com o objetivo de dar apoio às empresas que surgiram baseadas na sua comunidade interna e externa.

No quadro 7 observa-se o número de atividades realizadas pela incubadora tecnológica da UTFPR no que se refere ao número de empresas participantes, assim como o número de produtos desenvolvidos.

Quadro 7 - Atividades da Incubadora Tecnológica da UTFPR

\begin{tabular}{|l|l|l|l|l|l|}
\hline Ano & $\begin{array}{l}\text { Número de Empresas } \\
\text { participantes }\end{array}$ & $\begin{array}{l}\text { Número de produtos } \\
\text { desenvolvidos }\end{array}$ & Ano & $\begin{array}{l}\text { Número de Empresas } \\
\text { participantes }\end{array}$ & $\begin{array}{l}\text { Número de produtos } \\
\text { desenvolvidos }\end{array}$ \\
\hline 2015 & 22 & 40 & 2010 & 13 & 74 \\
\hline 2014 & 21 & 41 & 2009 & 19 & 77 \\
\hline 2013 & 22 & 62 & 2008 & 23 & 74 \\
\hline 2012 & 23 & 74 & 2007 & 26 & 65 \\
\hline 2011 & 17 & 58 & 2006 & 27 & 65 \\
\hline
\end{tabular}


\begin{tabular}{|l|l|l|}
\hline 2005 & 29 & 74 \\
\hline
\end{tabular}

Através do histórico da incubadora de inovações da UTFPR, visualizado no quadro 7, observa-se que o número de empresas incubadas se manteve praticamente constante, entre 0 período de 2006 a 2015, em parte pela limitação do espaço físico para este tipo de atividade. Já o número de produtos desenvolvidos também oscilou pouco, sendo menos expressivo nos últimos anos, demonstrando queda. Esses números mostram que o processo de incubação de empresas na UTFPR está estável, com suas metodologias de funcionamento estabelecidas. 0 que as ações internas poderiam refletir é sobre como estimular um maior número de desenvolvimento de produtos conforme os potenciais locais para que a UTFPR se consolide como um polo de inovação e empreendedorismo no Paraná.

\section{Conclusão}

O objetivo desta pesquisa foi verificar o papel da Universidade Tecnológica Federal do Paraná (UTFPR) no sistema regional de inovação no período de 2005 até 2015, por meio da interação da UTFPR com as empresas considerando as políticas nacionais e paranaenses.

A UTFPR tem representatividade regional, pois dos 399 municípios paranaenses, em 21 há instituições de ensino, e ela está presente em 13 desses municípios. Hoje ela forma mais de 2.300 profissionais, possui 28.551 alunos em diversos níveis de ensino, do técnico à pós-graduação e estabelece contínuos vínculos com o seu entorno por meio de oferta de estágios, visitas técnicas e gerenciais, cursos de qualificação e in company, grupos de pesquisa e contratos de transferência de tecnologia.

O Sistema regional de inovação paranaense é um sistema pujante que tem se modificado para promover mais ações inovadoras de forma coletiva entre as ações do governo, indústria e academia. As ações recentes de promoção de leis, que estimulam mais atividades inovadoras por parte das empresas, além de mais estímulos aos docentes pesquisadores por meio das leis nacionais de inovação (2004 e 2016); como também a lei regional de inovação tem afetado positivamente a interação entre estes agentes, ainda que em ritmo lento. A UTFPR, como agente 
importante neste sistema, sendo uma instituição de ensino público e federal, tem sido estimulada por tais regulações, no entanto, os recentes cortes financeiros para o seu custeio e investimento também afetam de forma negativa maiores avanços, principalmente nas atividades de pesquisa científica e tecnológica.

Ao caracterizarmos a UTFPR como agente partícipe do sistema regional paranaense de inovação, constata-se que ela migrou de um modelo Laissez-faire para o Hélice Tríplice (ETZKOWITZ, 2008), pois ao se constituir como universidade foram instituídas várias ações que a aproximam desse modelo, tais como, espaços promotores de empreendedorismo por meio do hotel tecnológico e incubadoras de empresas, além de tecnologias criadas pelos seus servidores e discentes, consultorias técnicas e contratos de transferência de tecnologia, cujas ações traduzem conhecimento em atividade econômica.

As formas de interação entre a UTFPR e indústria local em todos os 13 municípios de atuação no estado paranaense mostram maiores fluxos e comunicações. Estas interações foram analisadas a partir de suas funções precípuas e fundamentadas nas seguintes atividades: estágios, visitas técnicas, cursos de treinamento in company e de qualificação profissional, grupos de pesquisa, transferências de tecnologias e promoção do empreendedorismo.

Como a UTFPR contribui para o sistema regional de inovação? A instituição possibilita que seus discentes tenham a oportunidade de exercer práticas no mercado de trabalho por meio de estágios. Dados recentes mostram que de um banco cadastral com cerca de 11 mil empresas cadastradas, 44\% delas possuem contratos vigentes envolvendo 4.597 estagiários. Além disso, os discentes também participam, frequentemente, de visitas técnicas, que possibilitam acesso às atuais práticas realizadas pelas empresas além de visualizarem seus modelos de tecnologias adotados. Dados recentes mostram ainda que houve uma queda de $13 \%$ nessas visitas, em parte decorrente dos próprios problemas de recessão econômica pelos quais as economias nacional e regional passaram nos últimos anos, afetando as disponibilidades das empresas para tais atividades. Outro tipo de visita muito comum e praticado pela instituição são as visitas gerenciais com a finalidade de prestar serviços de consultorias técnicas e de qualificação profissional por meio de cursos in company e de qualificação. Nos últimos anos, constata-se uma queda na sua oferta, em torno de $32 \%$, em parte porque o perfil de seu docente tem-se modificado de um servidor voltado para dar respostas aos problemas da indústria, quando a instituição era focada na formação 
profissional, para servidor doutor, com regime de trabalho de dedicação exclusiva e com foco na pesquisa e produção científica. Com isso, a maior perda foi principalmente na realização de consultorias técnicas. Já os cursos de qualificação e in company crescem em torno de $45 \%$, registrando 7.537 matriculados em 2016.

Em relação aos grupos de pesquisa (GP), a UTFPR está entre as três primeiras universidades da região com maior número de GP cadastrados no CNPq, totalizando 461 grupos. A maioria desses grupos é recente, com menos de quatro anos (47,8\%), relacionado à área de engenharia com foco em pesquisas aplicadas (45,2\%). Estes dados mostram que, por ser uma universidade jovem, muitos desses grupos ainda estão se consolidando, além de sua tradição no ensino e formação de engenheiros, o que também justifica seu perfil de pesquisa. Esses grupos são importantes no sistema regional de inovação porque podem ser formados em parcerias com outros agentes, tais como outras universidades e institutos de pesquisa, a indústria e o governo para fins de desenvolvimento de pesquisa básica ou aplicada, científica ou tecnológica. Por outro lado, dados comparados entre 2006-16 mostram que esse número cresceu em 406,6\%, sendo mais expressivo nos últimos dois anos.

Dos 461 GP, 33,8\% deles mantêm interação com a indústria e apresentam taxa de crescimento mais elevada se comparada ao dos GP como um todo, registrando $766,67 \%$. E, dados recentes mostram que estão envolvidos com essas atividades de pesquisa com interação com a indústria, 3.355 alunos e 2.285 servidores.

Em relação aos contratos de transferência de tecnologia, que são coordenados pelos NIT por meio da Agência de Inovação da instituição, dos 183 realizados em 2016, o tipo mais usual foi o acordo de parceria de pesquisa, desenvolvimento e inovação, com 75 contratos estabelecidos. Demais parcerias também relevantes são os contratos ou convênio de permissão de utilização de laboratórios, equipamentos, instrumentos, materiais e instalações (43 objetos); e os contratos de know-how envolvendo ativos intangíveis não amparados por direitos de propriedade intelectual, assistência técnica (contração de soluções técnicas ou capacitação e treinamento) e demais serviços (46 objetos). Os de menor frequência foram os acordos de confiabilidade (12), os contratos de co-titularidade (9) e os contratos de licenciamento de direitos de propriedade intelectual (8). E, apesar de todas essas iniciativas, barreiras como o sigilo, a propriedade intelectual, a complexidade 
de contratos e as barreiras legais inerentes à transferência de tecnologia geram incertezas para as empresas e dificultam a sua maior interação com a UTFPR.

Por fim, a UTFPR também contribui para o sistema regional de inovação paranaense por meio de ações empreendedoras ao criar o Hotel Tecnológico e o espaço para incubação de empresas. Até hoje, ela já capacitou 120 empresas com potencial inovador apresentando aumento em torno de $24 \%$ no número de empresas instaladas no hotel, tendo atualmente 53 empresas instaladas. E, o número de alunos vinculados com essas atividades também tem aumentado em torno de 40\%, e o último dado mostra que havia 139 alunos envolvidos com atividades no hotel tecnológico. $O$ espaço de incubação é outra oportunidade para fomentar o empreendedorismo nos discentes. Atualmente, têm-se 22 empresas incubadas, número que não tem variado nos últimos anos dada a restrição física do espaço, além de uma queda no número dos produtos desenvolvidos por essas empresas; de 74 produtos, em 2010, para 40, em 2015. A partir deste quadro, como estimular um maior número de desenvolvimento de produtos, segundo as potencialidades econômicas locais? Pensar sobre isto é um importante passo para que a UTFPR se consolide como um polo de inovação e empreendedorismo no Paraná.

Vale ressaltar ainda que os resultados apresentados não têm pretensão de serem conclusivos, mas sim, de incentivar pesquisas futuras quanto à importância das universidades nos sistemas regionais de inovação. 


\section{Referências}

AMADEI, J.; TORKOMIAN, A. As patentes nas universidades: análise dos depósitos das universidades públicas paulistas. Ciência da Informação, v.38, n.02, p.9-18, 2009.

BALBACHEVSKY, E.; BOTELHO, A. Science and Innovation policies in Brazil: a framework for the analysis of change and continuity. In: IPSA-ECPR. Joint Conference: whatever happened to NorthSouth? Universidade de São Paulo, Brasil, 16 a 19 fev. 2011. São Paulo: 2011.

BASTOS, A. Perfil de Transferência de Tecnologia das Universidades Públicas Brasileiras Inovadoras. 2017. Dissertação (Mestrado em Planejamento e Governança Pública) - Programa de Pós-Graduação em Planejamento e Governança Pública, Universidade Tecnológica Federal do Paraná, Curitiba, 2017.

BOTELHO, A.J.J; ALVES, A.S. Uma avaliação da dinâmica das relações universidade-empresa para a inovação no Brasil. Evidências de duas experiências nacionais. Redes, v.17, n.32, p.223-243, jun. 2011.

BRASIL. Lei n. ${ }^{\circ} 10.973$, de 02 de dezembro de 2004. Dispõe sobre incentivos à inovação e à pesquisa científica e tecnológica no ambiente produtivo e dá outras providências. Diário Oficial da República Federativa do Brasil. Brasília, DF, 02 dez., 2004.

BRASIL. Lei n. ${ }^{\circ} 13.243$, de 11 de janeiro de 2016. Dispõe sobre estímulos ao desenvolvimento científico, à pesquisa, à capacitação científica e tecnológica e à inovação. Diário Oficial da República Federativa do Brasil. Brasília, DF, 12 jan., 2016.

CASSIOLATO, J. E.; LASTRES, H. M.M. Sistemas de inovação e desenvolvimento: as implicações de política, São Paulo em Perspectiva, São Paulo, v.19, n.1, p.34-45, jan. mar. 2005.

CNPQ. Diretório dos Grupos de Pesquisa no Brasil. (2015). Disponível em: <http://lattes.cnpq.br/web/dgp/painel-dgp/>. Acesso em: 06 set. 2016.

COHEN, W. M.; NELSON, R. R.; WALSH, J. P. The influence of public research on industrial R\&D. Management Science, v.48, n.1, p.1-23, 2002.

COOKE, P., BOEKHOLT, P.; TODTLING, F. The Governance of Innovation in Europe: regional perspectives on global Competitiveness. London: Pinter, 2000.

CORRÊA, F. A patente na universidade: contexto e perspectivas de uma política de geração de patentes na Universidade Federal Fluminense. 2000. (Dissertação Mestrado em Ciência da Informação). Universidade Federal Fluminense, Niterói, RJ, 2000.

DEBACKERE, K.; VEUGELERS, R. The role of academic technology transfer organizations in improving industry science links. Research Policy, v.34, n.3, p.321-342, 2005.

DECTER, M.; BENNETT, D.; LESEURE, M. University to business technology transfer - UK and USA comparisons. Technovation, v.27, p. 145-155, 2007. 
DIAS, A. A.; PORTO, G. S. Como a USP transfere tecnologia? Organizações e Sociedade, v. 21, n. 70, set. 2014.

DOLOREUX. D.; PARTO, S. Regional innovation systems: a critical review. 2004. Disponível em:<http://www.ulb.ac.be/soco/asrdlf/documents/RIS_Doloreux-Parto_ooo.pdf >. Acesso em: 04 set. de 2016.

DOULOUREUX, D. Regional Innovation Systems in the periphery. The case of Beauce in Quebec. International Journal of Innovatiom Management. v.7, n.1, p.67-94, 2003.

DOSSA, A. A. A cooperação tecnológica entre Universidades e institutos públicos de pesquisa no setor agropecuário brasileiro: um estudo na EMBRAPA. 2010. 209 f. Dissertação (Mestrado em Administração) - Programa de Pós-Graduação em Administração Universidade Federal do Paraná, Curitiba, 2010.

ETZKOWITZ, H. and LEYDESDORFF L. (Eds) Universities in the Global Economy: ATriple Helix of University-Industry-Government Relations. London: Cassell Academic, 1997b.

ETZKOWITZ, H. The evolution of the entrepreneurial university. International Journal Technology and Globalization, [S.I.], v.1, n.1, p.64-77, 2008.

ETZKOWITZ, H.; LEYDESDORFF, L. Introduction to the special issue on science policy dimensions of triple helix of university-industry-government relations, Science \& Public Policy, [S.I.], v.24, n.1, p.25, 1997 a.

FERNANDEZ, C. Cómo Construir un Sistema de Transferencia de Tecnología em un País em Desarrollo. In: ANGUITA, P. et al. Gestión de laPropiedad Intelectual e Innovaciónen Agricultura y em Salud: um manual de buenas prácticas. FIA: Programa FIA-PIPRA (Chile) y PIPRA (USA), 2010. Disponibleen línea:< http://fia.pipra.org>.

FREEMAN, C.; PEREZ, C. Structural crises of adjustment: business cycles and investment behaviour. In: DOSI et al., p.38-66, 1988.

FUJINO, A.; STAL, E. Gestão da propriedade intelectual na universidade pública brasileira: diretrizes para licenciamento e comercialização. Revista de Negócios, v.12, n.1, p.104-120, 2007.

GIULIANI, E.; ARZA, V. What drives the formation of 'valuable' university-industry linkages? Insights from the wine industry, Research Policy, v.38, n.6, p.906-921, 2009.

GRIMALDI, R.; KENNEY, M.; SIEGEL, D.S.; WIRGHT, M. 30 years after Bayh-Dole: Reassessing academic entrepreneurship. Research Policy, v.40, n.8, p.1045-1057, 2011.

INSTITUTO BRASILEIRO DE GEOGRAFIA E ESTATÍSTICA - IBGE. Pesquisa de Inovação: 2014, Coordenação de Indústria. Rio de Janeiro: IBGE, p.105, 2016.

KENNEY, M., MOWERY, D.C. Introduction. Chapter 1. In: KENNEY, M; MOWERY, D.C. (eds). Public Universities and Regional Growth - Insights from the University of California. California: Stanford University Press, 2014. 
LAURSEN, K; SALTER, A. Searching high and low: what types of firms use universities as a source of innovation? Research Policy, v.33, p.1201-1215, 2004.

LOCKETT, A., SIEGEL, D., WRIGHT, M., ENSLEY, M. The creation of spin-off firms at public research institutions: managerial and policy implications. Research Policy, v.34, n.7, p.981-993, 2005.

LUNDVALL, B.A. National Systems of Innovation: Towards a Theory of Innovation and Interactive Learning. London: Pinter Publishers, 1992.

MALERBA, F. Sectoral Systems of Innovation, Research Policy, v.31, p.247-264, 2002.

MOWERY, D.; SAMPAT, B. Universities in national innovation systems. In: FARGERBERG, J; MOWERY, D.; NELSON, R. (Eds.) The Oxford handbook of innovation. Oxford: Oxford University, 2005 .

NELSON, R. R. (Ed.). National innovation systems: A comparative analysis. Oxford: Oxford University Press, 1993.

PEDROSA, R.H.L. A inovação tecnológica e a "terceira missão das universidades". Campinas: DPCT/Unicamp, 2014.

PEDROSA, R.H.L; QUEIROZ, S.R.R. Democracia e o "dividendo de inovação" -Brasil. In: SCHWARTZMAN, S. (org.). A via Democrática: como o desenvolvimento econômico e social ocorre no Brasil. Rio de Janeiro: Elsevier, 2014, p.135-176.

SANTANA, E.; PORTO, G. E agora, o que fazer com essa tecnologia? Um estudo multicaso sobre as possibilidades de transferência de tecnologia na USP-RP. Revista de Administração Contemporânea, v.13, n.3, art.4, p.410-429, 2009.

SEGATTO-MENDES, A. P.; SBRAGIA, R. O processo de cooperação universidade-empresa em universidades brasileiras. Revista de Administração, São Paulo v.37, n.4, p.58-71, out./dez. 2002.

SIEGEL, D. S., P. WESTHEAD, P.; WRIGHT, M. Assessing the Impact of Science Parks on the Research Productivity of Firms: Exploratory Evidence from the United Kingdom, International Journal of Industrial Organization, v.21, n.9, p.1357-1369, 2003b.

SIEGEL, D. S; VEUGELERS, R.; WIRGHT, M. Technology transfer offices and commercialization of university intellectual property: performance and policy implications, Oxford Review of Economic Policy, v.23, n.4, p.640-660, 2007.

SIEGEL, D.S., WALDMAN, D.A., LINK, A.N. Assessing the impact of organizational practices on the productivity of university technology transfer offices: an exploratory study. Research Policy, v.32, n.1, p.27-48, 2003 a.

SILVA, M. C.; CASIMIRO, A. H. T.; DUARTE, E. N. Caracterização dos grupos de pe squisa em inteligência organizacional competitiva. Biblionline, João Pessoa, v. 12, n. 1, p. 14-25, 2016. Disponível em: <http://www.ies.ufpb.br/ojs/index.php/biblio/article/view/ 27971>. Acesso em: 1 set. 2016. 
UNIVERSIDADE TECNOLÓGICA FEDERAL DO PARANÁ. Relatório de Gestão: Exercício 2016, 2015, 2014, 2013, 2012, 2011, 2010, 2009, 2008, 2007, 2006, 2005. Curitiba. Disponível em:http://www.utfpr.edu.br/estruturauniversitaria/diretorias-de-gestao/diretoria-de-gestao-daavaliacao-institucional/relatorios-de-gestao. Acessado em: 12 de set. 2016.

VAN LOOY, B Et al. Combining entrepreneurial and scientific performance in academia: towards a compounded and bi-directional Mattheweffect. Research Policy, v.33, p.425-441, 2004.

YUSUF, S. University-Industry Links: Policy Dimensions. In: YUSUF, S.; NABESHIMA, K. How Universities Promote Economic Growth. Washington: The World Bank, 2007. 